\title{
National geoparks initiated in China: Putting geoscience in the service of society
}

\author{
1.Chinese Academy of Geological Sciences, Baiwanzhuang Road, Beijing 100037, China. \\ 2.Geological Society of China, Baiwanzhuang Road, Beijing 100037, China.
}

\begin{abstract}
The heritage of geological history is a legacy bestowed upon us by Nature. It is mankind's obligation to protect $i t$, so that it can be a benefit to posterity for ever. The best way to ensure geoheritage conservation is by the construction of Geoparks to aid geoscientific research and serve as sites of propagation of scientific knowledge. Geoparks attract visitors, and at the same time create local jobs and develop the local economy. In addition, they are means by which the local government can enforce environmental protection based on more enthusiastic support from the local people with the development of their economy.

China set up 11 national Geoparks for the first time in the year 2000, under the guidance of the UNESCO Earth Science Division, and hence has become one of the pioneers in this aspect. Doubtless, the conservation of the geological heritage will become more and more effective as a result of the setting up of these parks.
\end{abstract}

\section{The development of National Geoparks Program in China}

Based on earlier initiatives, and with support from UNESCO, the International Union of Geological Sciences (IUGS) started to compile a global inventory of key geoscience localities and terrains in 1995 (W. Wimbledon et. al, 1998). To keep abreast of the work of geoscientists in other countries, the geoscience community of China attaches great importance to the conservation of geosites, in order to reach the goal of sustainable development, i.e. development which meets the needs of the present generation without compromising the ability of future generations to meet their own needs, defined by the World Commission on the Environment and Development in our Common Future (1987).

Extensive geological surveys may identify a number of national or regional geosites for conservation (Wimbledon et al., 1999). The conservation of geological sites started in China in the 1980s, and has been conducted ever since in accordance with national laws and regulations, supported by government agencies and promoted by nongovernmental organizations (Pan Jiang, et al., 1996). Through the efforts of the past two decades, 138 conservation spots (or districts) have been established as Geosites, and 325 more are planned. The level of conservation varies from place to place. In general, one can say that isolated spots are subject to damage, while conjunctive ones or those located in natural scenic spots are well preserved. Since 1992, W. Eder, Director of UNESCO's Division of Earth Sciences, has favoured the initiation of "Geoparks" in cooperation with Geosite conservation (W. Eder, 1999, 2001). At an international experts meeting on Geoparks organized at UNESCO's Paris headquarters on Feb. 9, 2001, a resolution paved the way for countries all over the world to initiate the establishment of national or regional Geoparks in collaboration with UNESCO's Division of Earth Sciences. In June 2001, the $161^{\text {st }}$ session of UNESCO's Executive Board urged UNESCO to support appropriate proposals if so requested by the member states. And thus the Geoparks initiative has taken a substantial step forward.

One of the most important starting points for the inclusion of geological heritage into the general line of the protection of our natural environment is the "International Declaration of the Rights of the Memories of the Earth" (Digne, France, 1991). The declaration recalled that "the Earth retains memories of its past. ... A record which is inscribed both in its depths and on the surface, in the rocks and in the landscapes, a record which can be read and translated." And "the Earth is 4.5 billion years old and the cradle of life, of renewal and of the metamorphosis of life; its long evolution, its slow rise to maturity, has shaped the environment in which we live".

Taking this into account, the setting up of conservation areas for geological sites can effectively preserve valuable geological features. Generally, geological or geomorphological structures are a result of long-term processes, and can never be renewed. Therefore, they represent a heritage that can not only provide objects for scientific study, but can also raise the level of the public's scientific understanding and their comprehension of the elegance and charm of nature. In addition, respecting and developing geological sites will undoubtedly promote and favour the conservation of our natural geo-ecological environment.

Over the past century or so, geoscientists have been working hard to do geological surveys and explorations in order to provide society with raw materials and fossil energy resources for industrial purposes, and made great contributions to economic development. But as time progresses, a trend from the industrial economy toward the knowledge economy gradually emerged; people are now paying more and more attention to a better quality of life and a better ecological environment. Geoscientists now recognize that there is information from the past hidden in the geological record that needs to be clarified, for instance, the emergence and mass extinction of biological species throughout the earth's history. Despite the progress in science and technology that has provided more and more advanced means and methods, these natural mysteries have not yet been resolved. Thus, if these vulnerable geological sites reflecting the ecological environment and living conditions of the past were to be destroyed, one could never unravel these questions. Moreover, many of these sites themselves are attractive natural scenic spots. In conjunction with the investigation and study of these geological heritage sites or areas, one could detect local economic development plans supporting selected sites, like mineral deposits or mines, in order to create geotourism bases.

Besides the possibilities provided for scientific research and broad environmental education, "Geoparks" may have a great potential for local sustainable socio-economic development. In China, the focus is the enhancement of employment and new economic activities linked to the specialties of each Geopark. The establishment of individual Geoparks should favour new orientations in tourism (geotourism), and in trades and crafts (geoproducts), such as the sustainable manufacturing of innovative handicrafts which have a geological connotation, for example fossil casting and souvenirs (UNESCO, 156 EX/11 Rev. Paris April 1999). 


\section{The first group of national geoparks in China}

From China's geological sites which have already been listed in the Global Inventory, 11 have been selected as National Geoparks (Figure 1). A brief description follows:

\section{Stone Forest National Geopark (Figure 2)}

This Geopark is located in southwest China's Yunnan Province, covering an area of $400 \mathrm{~km}^{2}$. Featuring a carbonate peak forest landform, it consists of Late Palaeozoic neritic limestone and dolomite. Especially in the thick massive carbonate rocks, there occur vertical joints, and when plentiful rainwater permeates and corrodes the joints, it brings about the formation of various karst landscapes, such as stone teeth, corroded gully, corroded funnel, peak forest, karst cave and dissolution basin. Magnificent peak forests of various forms characterize the area, looking like pillars, swords, pagodas, mushrooms, human figures, exotic animals, etc. Ranging from $20 \mathrm{~m}$ to $50 \mathrm{~m}$ in height, the sections stand erect, looking from a distance like a forest, hence the name Stone Forest. The area is inhabited by people of the Yi nationality. Ancient rock paintings and stone inscriptions in the ancient Yi characters have been discovered in many places here. Visitors can observe the folk customs and local culture while enjoying the scenic beauty.

\section{Zhangjiajie Sandstone Peak Forest National Geopark (Figure 3)}

Located in the western part of Hunan Province, South China, the Zhangjiajie Sandstone Peak Forest National Geopark is known for its quartzose sandstone landform, covering an area of $3600 \mathrm{~km}^{2}$. The thick beds of Devonian quartzose sandstone in the area occur flatlying, with well-developed vertical joints dipping NE, NW and NS. Undergoing natural processes like current scouring and rock collapse, and depending on the duration of exposure and the maturity of fissures, the sandstone assumes a variety of forms, such as hills, walls, pillars, gates, natural bridges, etc. Altogether, there are more than 3,000 sandstone peaks, among which over 1,000 are higher than 200 $\mathrm{m}$; the highest, Jinbian Rock, soars $350 \mathrm{~m}$. Special attractions there are the pine and ginkgo trees standing at the top of the peaks, with an exuberant growth of branches and leaves and twisted roots, just like an enlarged potted landscape. The area is picturesque, with verdant hills, clear waters, crisscrossed gullies, and a wide variety of flora and fauna, making it an attractive place for holiday-making and tourism.

\section{Songshan National Geopark (Figure 4)}

Located in the northern part of Henan Province, Central China, and with an area of $450 \mathrm{~km}^{2}$, Songshan National Geopark is famous for its complete outcrops of stratigraphic section and the boundaries of angular unconformities formed by three Precambrian tectonic movements. There are found outcrops of the Archean, Proterozoic, Paleozoic, Mesozoic and Cenozoic. The Songyang Movement of $2300 \mathrm{Ma}$, the Zhongyue Movement of $1850 \mathrm{Ma}$ and the Shaolin Movement of $570 \mathrm{Ma}$ were named after localities in the area. The boundaries of angular unconformities and basal conglomerates are very distinguishable. So it is referred to as a "textbook of geological history." The area is also an assembly point of three major religions in China - Buddhism, Confucianism and Taoism - and one of the birthplaces of China's ancient culture, where one can hear the sound of ancient bells and drums, and view many historical and religious remains such as Buddhist temples and pagodas, Taoist temples and ancient academies of classical learning. The geological and cultural sites form a delightful contrast, making the area an ideal tourist attraction.

\section{Lushan National Geopark (Figure 5)}

Covering an area of $500 \mathrm{~km}^{2}$, Lushan National Geopark is situated in the northern part of Jiangxi Province, East China, bordering Poyang Lake on the east and extending to the Yangtze River. Owing to the uplifting of horst [??] structure, the area is characterized by fault-block mountains, with towering peaks, lush flowers and trees, rolling torrents of water, deep pools and waterfalls down. Old dwellings and pavilions nestling in the mountains are an added attraction. In the 1930s Prof. J. S. Lee identified the Quaternary glacier sections there. There sections are well preserved, and glacier evidence is clearly discernible. In addition, this area is where a number of major incidents in Chinese history in the last century took place.

\section{Chengjiang Fauna National Geopark (Figure 6)}

This Geopark is located in the Tianmaoshan Mountains area of Chengjiang County, Yunnan Province, Southwest China, with an area of $18 \mathrm{~km}^{2}$. It is home to about 40 phyla of early Precambrian fauna and more than 100 kinds of precious zoolite, such as invertebrate and notochord fossils. The most valuable aspect of the area is the fact that representatives of the remote ancestors of all the present organisms have been discovered in this area, including the mold of both zoaria and mollusks. It offers profound and precise information for studying the physiology, living habits, systematic evolution and ecological environment during the flourishing period of Precambrian primitive animals. Moreover, the neighboring Fuxian Lake is a Quaternary fault basin in origin, and there are remains of ancient towns at the bottom of the lake. It is expected to become a base for scientific research and the popularization of science.

\section{Wudalianchi Volcanoes National Geopark(Figure 7)}

This Geopark is located in Wudalianchi, Heilongiiang Province, Northeast China. It covers an area of $720 \mathrm{~km}^{2}$, and is composed of 14 intact recent volcanoes, 12 of which erupted 12 Ma-1 Ma ago and 2 erupted 1,719-1,721 years ago. The volcanic cones are complete, and the lava flows stretch for as far as over $10 \mathrm{~km}$, thus blocking the rivers around to bring about the five lakes spreading in the form of a string of breads. The lava assumes various shapes and forms, for instance, exhalation vent, cone and dish, lava tunnel, volcanic bomb and traveled stone. Even ropy lavas and twisted lavas are kept intact there. There are also plentiful mineral springs with medicinal value in the area, attracting many visitors.

\section{Zigong Dinosaurs National Geopark (Figure 8)}

This Geopark is located in Da'anzhai, Zigong City, Sichuan Province, Southwest China, covering an area of $8.7 \mathrm{~km}^{2}$. Many Middle Jurassic dinosaur fossils and other vertebrate fossils have been discovered here. Within the excavated area of $2,800 \mathrm{~m}^{2}$, more than 200 zooids have been determined, and over 10,000 skeletons have been identified, including those of Dinosaurs, Chelonia, Crocodilia, Pterosauria, fish, Amphibia and mammal-like reptiles, which belong to 18 genera and 21 species (of which 21 are newly discovered species). These fossils involve so many families and are so well preserved that they have very important scientific value. The adjacent salt wells, the oldest of their kind in the world, are still in good condition, and the drilling and digging techniques of the ancient Chinese evoke the admiration of visitors.

\section{Zhangzhou Littoral Volcanoes National Geopark (Figure 9)}

Located in the littoral zone of Zhangpu-Longhai, Zhangzhou City, Fujian Province, Southeast China, the Zhangzhou Littoral Volcanoes National Geopark covers an area of $318.64 \mathrm{~km}^{2}$. Volcano and marine-erosion landforms are well developed here. As part of the west circum-Pacific volcanic rock belt, it belongs to the rifted zone on the eastern margin of the Eurasian plate. Basalts which erupted 26 Ma-7 Ma ago are exposed along the coasts and on the islands, showing clearly the sequence of eruptions, such as craters, exhalative vents, and vesicle cylinder clusters. There are also various marineerosion landforms, for instance, majestic columnar joints, seaworn mushroom rocks, marine-cut platforms, marine cliffs and marine caves. Dozens of broad and smooth sand beaches stretch along the coast. Here, visitors can enjoy viewing the remains of old forests buried for 8,000 years because of coastal subsidence, the houses of ancient inhabitants and old military fortresses. 


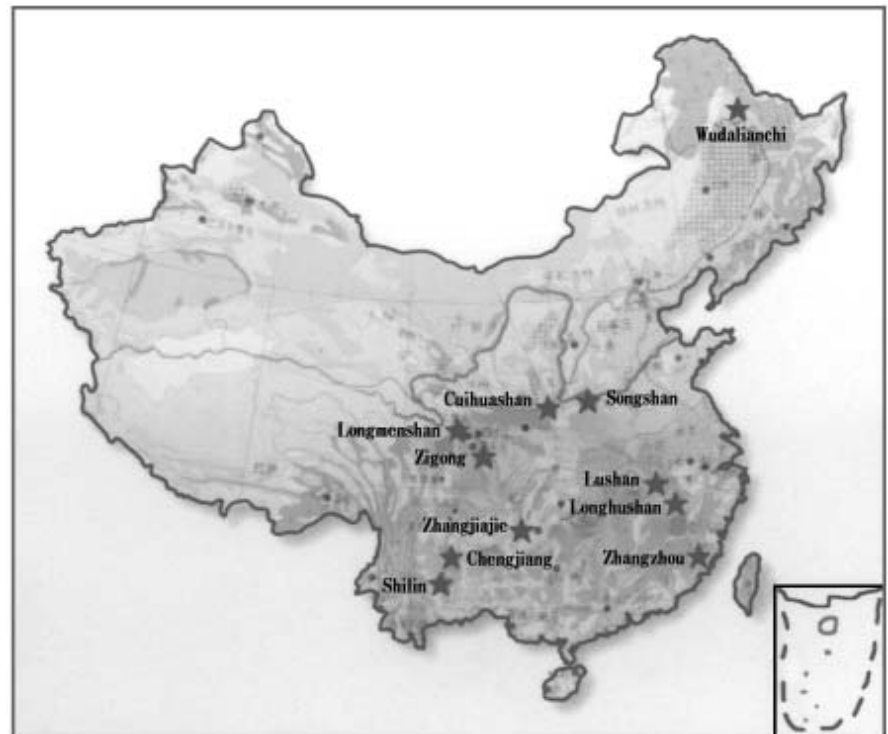

Figure 1 Distribution of eleven national geoparks in China.

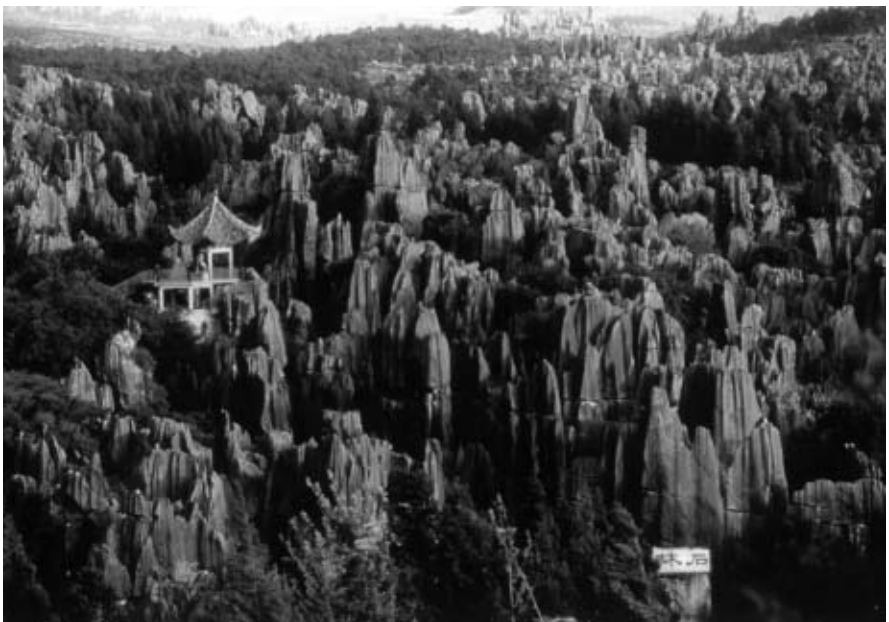

Figure 2 Shilin National Geopark: the stone forest.

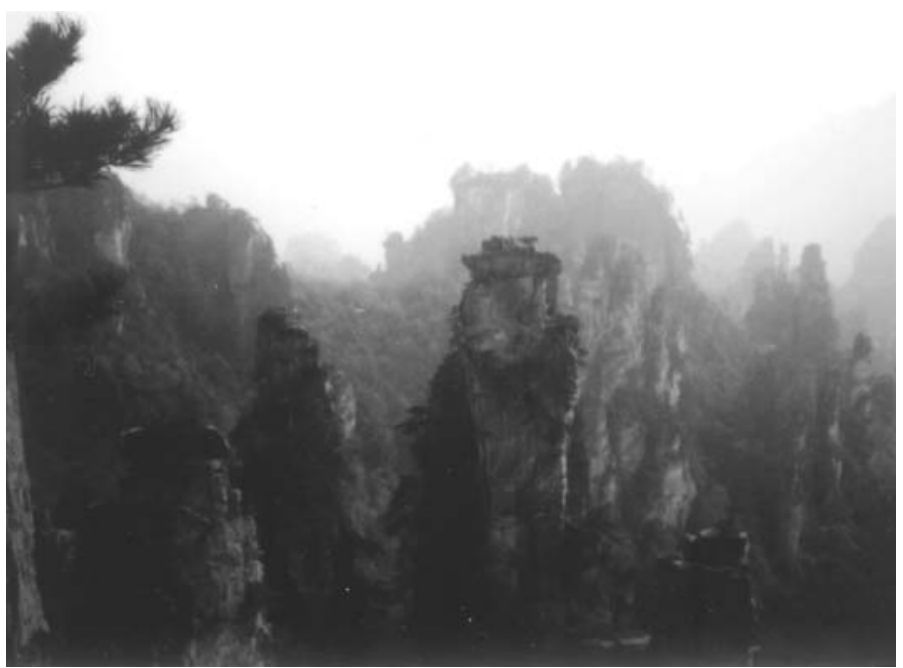

Figure 3 Zhangjiajie national geopark: peaks of sandstone, $100-300 \mathrm{~m}$ in height.

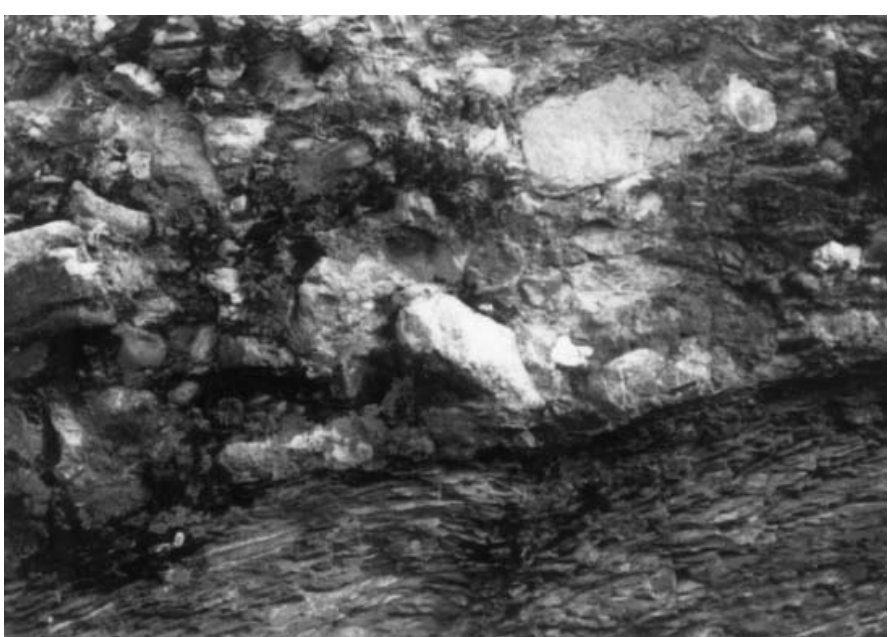

Figure 4 Songshan National Geopark: unconformity and basal conglomerate formed by Saoling movement, $570 \mathrm{Ma}$.

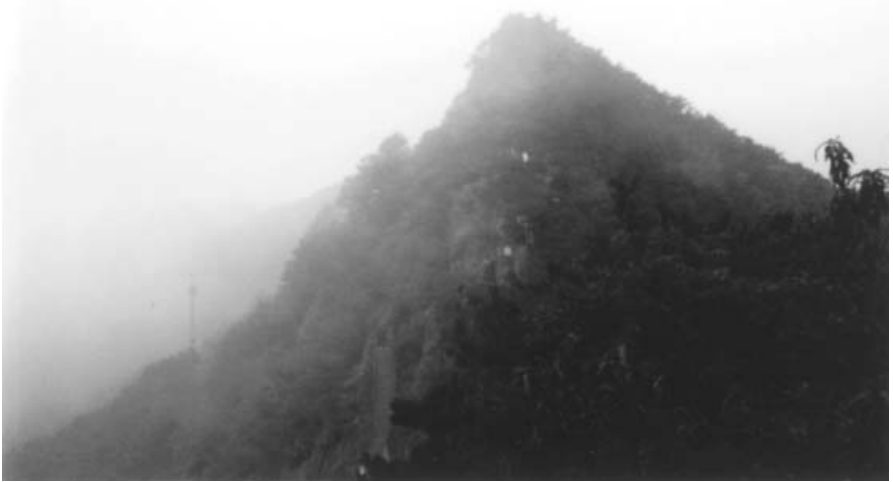

Figure 5 Lushan National Geopark: Quaternary glacier traces.

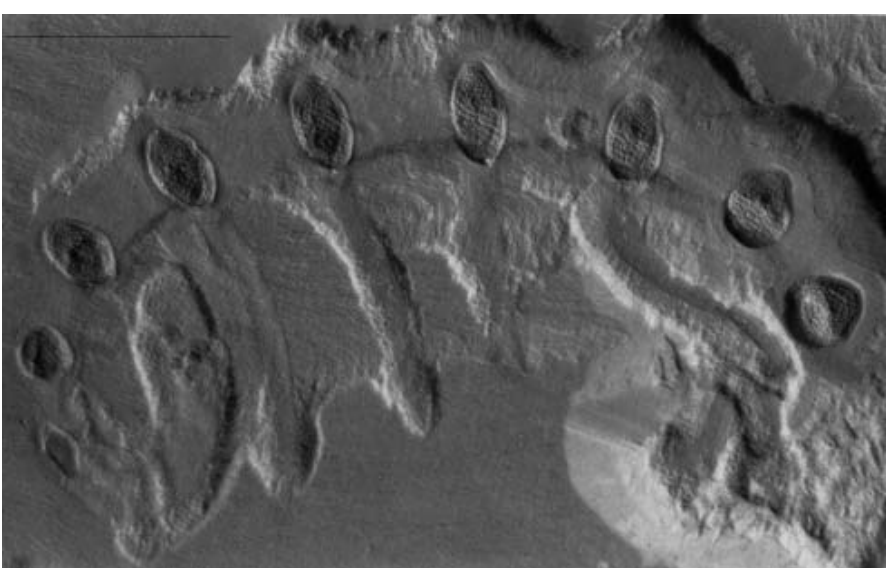

Figure 6 Chengjiang National Geopark: Microdictyon sinicum from Maotianshan, Chengjiang. 


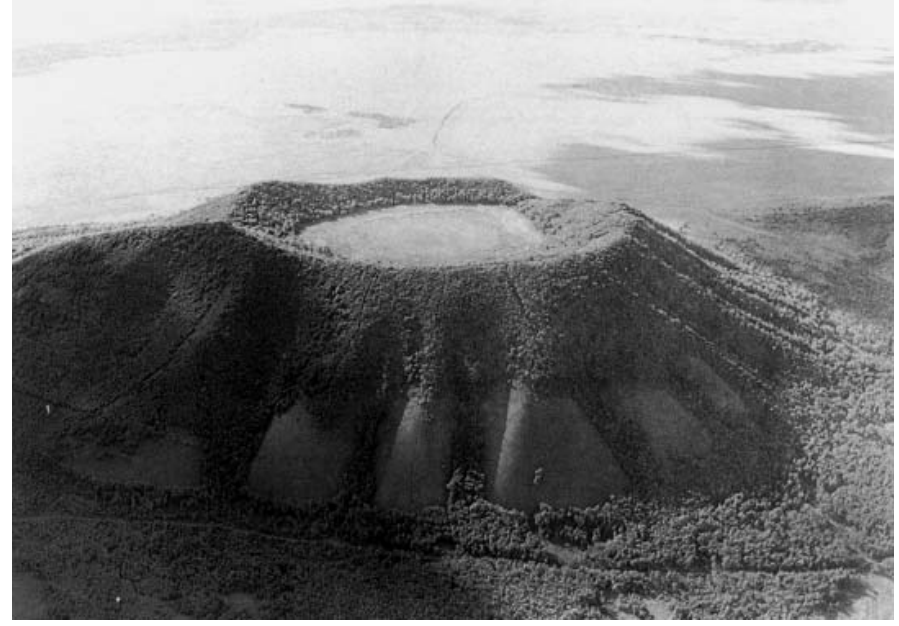

Figure 7 Wudalianchi National Geopark: volcanoes.

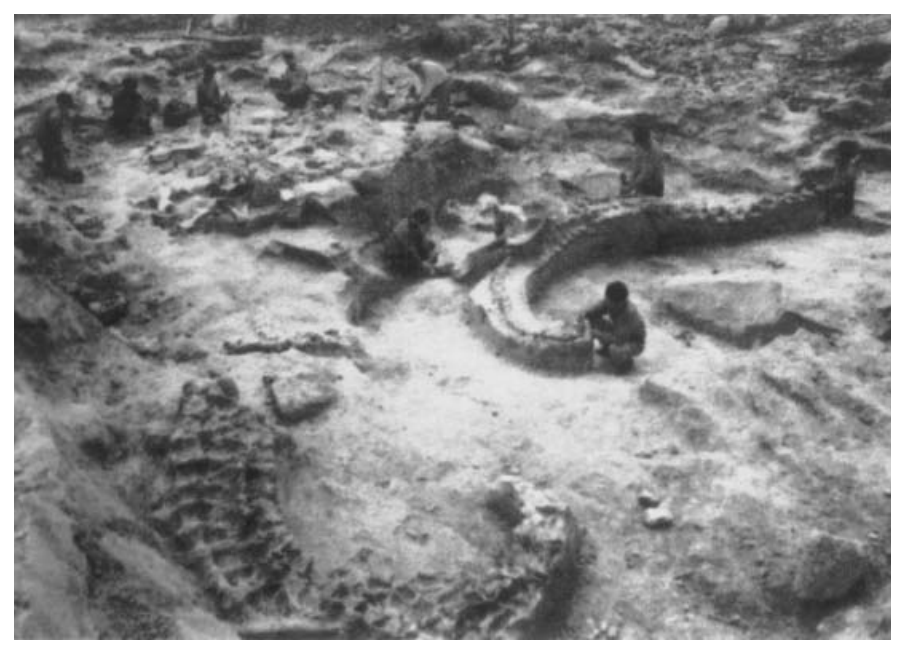

Figure 8 Zigong National Geopark: unearthed dinasour skeletons.

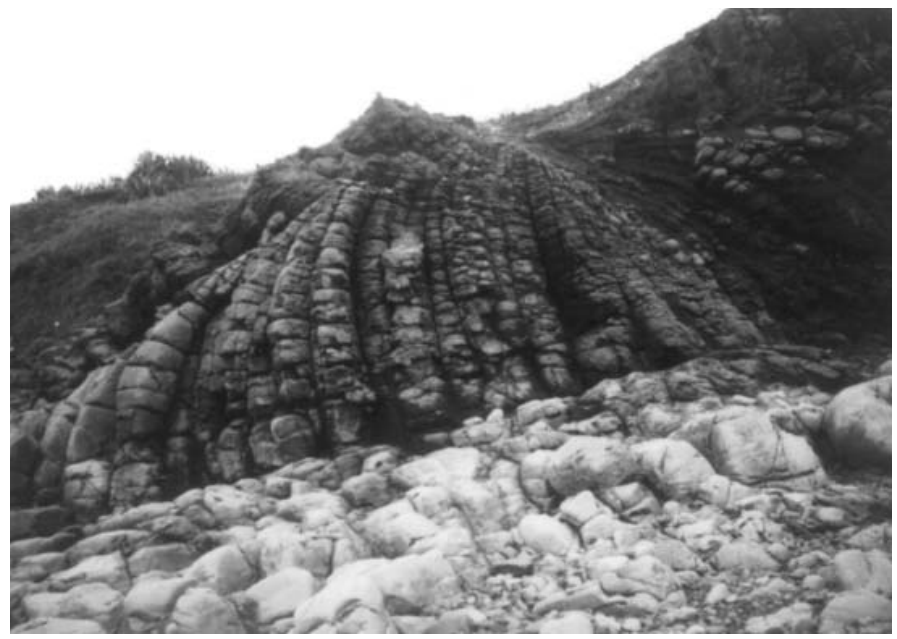

Figure 9 Zhangzhou National Geopark: columnar joint of basalt.

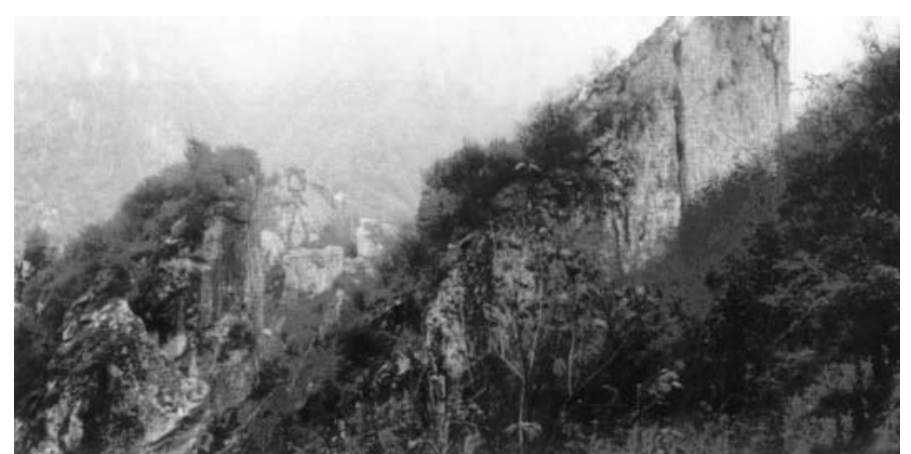

Figure 10 Cuihuashan National Geopark: collapse and slides caused by strong fault activity.

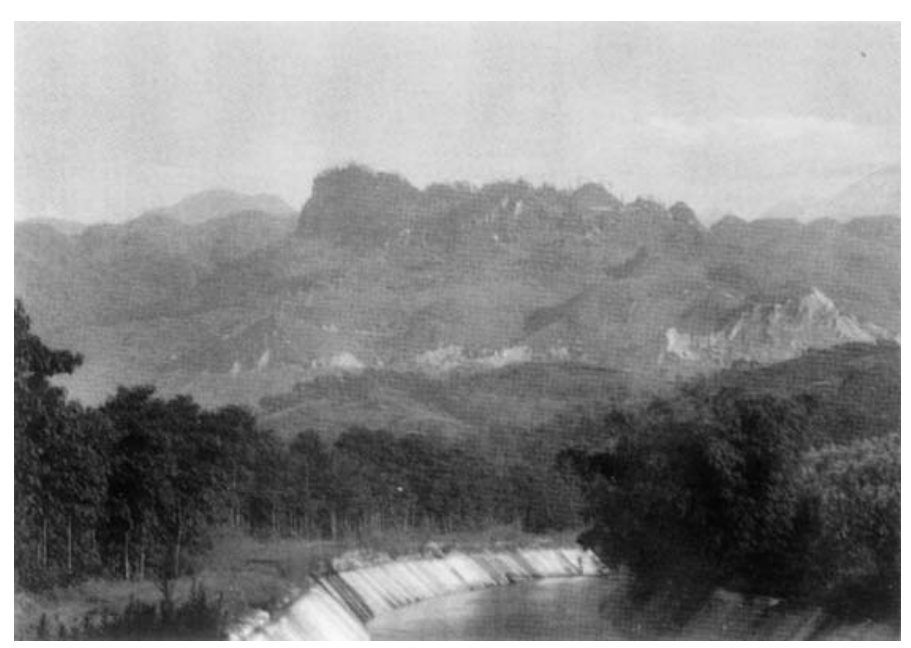

Figure 11 Longmenshan National Geopark: Nappe outlier.

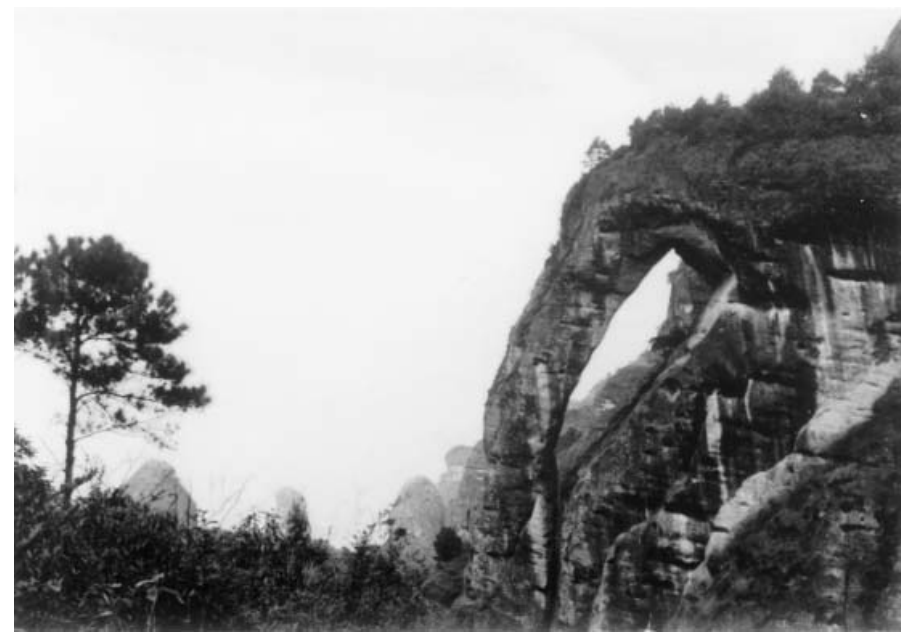

Figure 12 Longhushan National Geopark: Danxia landscape. 


\section{Cuihuashan Landslides National Geopark (Figure 10)}

Situated in Chang'an County, Xi'an City, in northwest China's Shaanxi Province, the Cuihuashan Landslides National Geopark occupies an area of $32 \mathrm{~km}^{2}$. It experienced a major faulting movement on the northern side of the Qinling Ranges. The southern wall of the fault is uplifting at a rate $1.73-3.4 \mathrm{~mm}$ per year, and earthquakes take place now and then. All of this induces fracturing and sliding of blocks, thus bringing about landslide-related landforms, like sheer cliffs and overhanging rocks, rock sea [??], piled caves, blocked-up lakes and waterfalls. Large collapsed blocks in unique and strange forms can be used both to study geological hazards and as an interesting place for the public to broaden their knowledge of earth sciences.

\section{Longmenshan National Geopark (Figure 11)}

The Longmenshan National Geopark is located at the juncture of Pengzhou, Shifang and Mianzhu cities, in southwest China's Sichuan Province, covering an area of $1900 \mathrm{~km}^{2}$. The rapid uplift of the Qinghai-Tibet Plateau led to the compression and napping of Mount Longmenshan towards the Sichuan Basin, hence forming a natural wonder of thrust outliers in the area. Moreover, Mount Longmenshan towers on the western margin of the Sichuan Plain. It is high and precipitous, covered with jagged rocks of grotesque shapes, and ornamented with green plants and clear waters. There are also remains of glaciers and well-preserved stratigraphic profiles. It is a place for both tourism and geological research.

\section{Mount Longhushan National Geopark (Figure 12)}

Located in Yingtan City, East Jiangxi Province, this Geopark is a typical Danxia landscape, occupying an area of $380 \mathrm{~km}^{2}$. Geotectonically it originated in a Mesozoic volcanic fault basin, resulting in the formation of purplish-red thick conglomerates of fluvio-lacustrine facies, sandstones and volcanic rocks. Under the impact of later processes such as water scouring through the fissures and eboulement, there appeared a variety of landforms including mesa, cuesta or hogback, stone stockade, wall, ridge, cliff, honeycomb cave, vertical cave, pillar, peak and peak cluster, and peak forest, associated with a series of natural landscapes such as strip of sky, natural bridge, gate and elephant trunk-shaped hill. The mountain area was also one of the major sites for Taoist practices in ancient times. Relics of ancient suspended coffins can be seen on the cliffs.

China, with a vast territory and long history, is proud of its unique geological settings, beautiful mountains and rivers, and esoteric culture. The ancient Chinese always attached great importance to the balance between man and nature, adhering to the philosophical concept of the harmony of Heaven and man. So they built academies of learning and temples, and erected tablets and pagodas for cultural activities and religious practices in well-known mountains and by major rivers. And in these localities there often exist quite a large

Zhao Xun is Executive Vice President and Professor of sedimentology in Chinese Academy of Geological Sciences. Born in 1942. Graduated from Chengdu Institute of Geology in 1966. number of geological sites. If we combine the conservation of historical sites of religious or cultural importance with the preservation of geological sites, these areas could become harmonious locations where human beings live in balance with the natural environment.

Geologists are able to add a lot to this new field of endeavor, and Chinese geologists have advantages in making contributions to the conservation of global geological sites.

Our history and the history of the Earth are closely linked. Its origins are our origins, its history is our history and its future will be our future (International Declaration of the Rights of the Memory of the Earth, 1991, Digne, France). Geological sites are a common heritage of mankind. To keep them intact is man's responsibility and the obligation of countries and geologists all over the world. Just as human life is recognized as being unique, the time has come to recognize the uniqueness of the Earth, and it is high time for people to see the future of the Earth based on learning about its past and present. Learning to protect global geosites is the very basis of this long-term process.

\section{Acknowledgement}

This work has been supported by the Ecoenvironment Department of the Ministry of Land and Resources of China, and the Chinese National Geoparks Leading Group. Grateful acknowledgement goes to Dr. W. Eder, Director of the Earth Sciences Division, UNESCO, for his instruction, encouragement and revision of this paper. We appreciate the enthusiastic work of the entire staff of the relevant Chinese governmental agencies and the Earth Sciences Division of UNESCO for their sponsorship for the initiation of the international network of Geoparks.

\section{References}

Cowie, J. W., and Wimbledon, W. A. P., 1994, The world heritage list and its relavance to geology. Proceedings of the Marvern Conference 1993, 71-73.

Eder, W., 1999, "UNESCO Geoparks"-A new initiative for protection and sustainable development of the Earth's heritage, N. Jb. Geol. Paläont. Abh. 214(1/2), 353-358.

International Declaration of the Rights of the Memories of the Earth, 1991, Digne, France.

Ji Shu'an \& Pan Jiang, 1997, The geological heritage sites and national parks in China. Engineering Geology and the Environment, Mannos, Köukis, Balkema, 2961-2965.

Wimbledon, W. A. P., et al., 1998, A first attempt at a geosites framework for Europe-An IUGS initiative to support recognition of world heritage and European geodiversity. Geologica Balcanica, 28, 3-4, Sofia, December 1998, pp.5-32.

Wimbledon, W. A. P., et al., 1999, Geological world heritage: Geosites-a global comparative site inventory to enable prioritisation for conservation. Mem. Descr. Carta. Geol. d'It. LIV 1999, pp. 45-60.

Wang Milly is Secretary General of Geological Society of China, Professor of salt lake geology. Born in 1941. Graduated from Peking University in 1965.

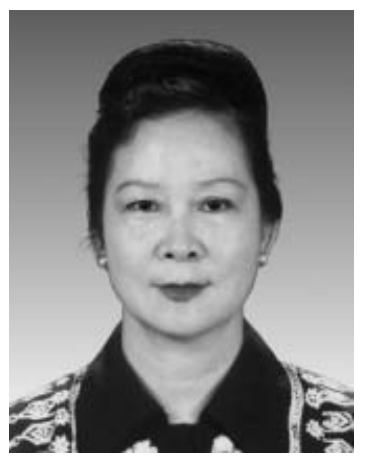

